\title{
Population Analysis
}

National Cancer Institute

\section{Source}

National Cancer Institute. Population Analysis. NCI Thesaurus. Code C18949.

Investigation of the component parts of a whole and the relationship between the parts,

frequently using statistical methods, of a defined set of individuals or items (population). 